\title{
Canagliflozin: a novel treatment option for type 2 diabetes
}

This article was published in the following Dove Press journal:

Drug Design, Development and Therapy

2I November 2013

Number of times this article has been viewed

\author{
Eric Dietrich' \\ Jason Powell ${ }^{2}$ \\ James R Taylor ${ }^{2}$ \\ 'University of Florida College \\ of Medicine, Department of \\ Community Health and Family \\ Medicine, ${ }^{2}$ University of Florida \\ College of Pharmacy, Department \\ of Pharmacotherapy and Translational \\ Research, Gainesville, FL, USA
}

Correspondence: Eric Dietrich University of Florida College of Medicine, Department of Community Health and Family Medicine, 1707 North Main Street, Gainesville, FL 32609, USA

Email eadII29@ufl.edu

\begin{abstract}
Type 2 diabetes continues to be a challenging disease to manage. The addition of new agents with a positive risk-benefit ratio could potentially assist clinicians and patients in achieving adequate diabetes control. Canagliflozin, the first sodium-glucose cotransporter 2 inhibitor presently available on the market, offers a unique mechanism of action: it inhibits renal reabsorption of glucose, thereby increasing urinary glucose excretion. It reduces hemoglobin $\mathrm{A}_{1 \mathrm{c}}$ by approximately $0.37 \%-1.16 \%$; it also reduces the patient's weight and systolic blood pressure and has a low risk for hypoglycemia. Adverse effects include an increased risk of urinary tract infections and genital mycotic infections. In this manuscript we review canagliflozin and its potential role in management of type 2 diabetes mellitus.
\end{abstract}

Keywords: canagliflozin, SGLT2 inhibitor, type 2 diabetes, oral hypoglycemic

\section{Introduction}

Diabetes affects 25.8 million people in the US, which accounts for more than $8 \%$ of the population; nearly 2 million new cases are diagnosed each year. ${ }^{1}$ In the late 1980 s, only about $2 \%$ of those with diabetes achieved all their therapeutic goals (using American Diabetes Association goals at time of study: hemoglobin $\mathrm{A}_{1 \mathrm{c}}\left[\mathrm{A}_{1 \mathrm{c}}\right]<7 \%$, blood pressure (BP) $<130 / 80 \mathrm{mmHg}$, and cholesterol goals (low-density lipoprotein [LDL] $<100 \mathrm{mg} / \mathrm{dL}) .{ }^{2}$ In 2010, the number of persons with diabetes reaching all their therapeutic goals had approached $20 \%$. While that is a significant increase, it is clear that the vast majority of patients with diabetes are not receiving optimal care. When considering therapeutic goals as of 2010, only a little over half (52.5\%) of patients with diabetes had achieved their $\mathrm{A}_{1 \mathrm{c}}$ goal, 51.1\% had achieved their blood pressure goal; and $56.7 \%$ had achieved their LDL cholesterol goal. ${ }^{2}$ Thus, whereas improvements have been seen over the past 2 decades, there is certainly more room for improvement. A number of new pharmacologic agents for type 2 diabetes mellitus (T2DM) have become available in recent years; their use as treatment may increase the number of patients reaching their therapeutic goals.

A number of injectable and oral medications are available for treating T2DM; each carries risks and benefits that must be considered to select the most appropriate therapy for the patient. Some factors to consider include $\mathrm{A}_{1 \mathrm{c}}$ and glucose reduction, dosing complexity, adverse events (AEs), effects on weight and cholesterol, cardiovascular (CV) effects, and cost. Metformin is generally considered the initial drug of choice for T2DM because of its highly favorable risk-benefit ratio. ${ }^{3}$ It usually produces $\mathrm{A}_{1 \mathrm{c}}$ reductions of $1 \%$ or greater, does not cause weight gain or hypoglycemia, does not adversely affect cholesterol, is inexpensive, and is generally well tolerated. Should a 
patient require addition of a second agent, the aforementioned factors must be accounted for when taking a patient-centered approach to diabetes management. Agents with multiple advantages may assist more people to reach their therapeutic goals. Canagliflozin (INVOKANATM; Janssen Pharmaceuticals, Johnson and Johnson, New Brunswick, NJ, USA) the first sodium-glucose cotransporter 2 (SGLT2) inhibitor available on the market, offers a unique mechanism of action: it inhibits renal reabsorption of glucose, thus increasing urinary glucose excretion. It also reduces weight and systolic blood pressure and has a low risk of hypoglycemia. AEs include increased risk of urinary tract infections (UTIs) and genital mycotic infections. In this manuscript, we review the potential role for canagliflozin in management of T2DM.

\section{Pharmacology and pharmacokinetics of canagliflozin}

Nearly all plasma glucose (PG) that is filtered at the glomerulus of the kidney is reabsorbed in the proximal tubule, with less than $1 \%$ being excreted into the urine. Reabsorption of the filtered glucose is mediated primarily by the glucose transporter protein SGLT2, and to a lesser extent, by the sodium-glucose cotransporter 1 (SGLT1). SGLT1 is located in the kidney, intestine, and heart, whereas SGLT2 is located primarily in the S1 segment of the proximal tubules; SGLT2 is responsible for reabsorbing $90 \%$ of the filtered glucose in the kidney ${ }^{4}$ and can reabsorb nearly all glucose filtered by the glomerulus up to a PG concentration of approximately $180 \mathrm{mg} / \mathrm{dL}$, the renal threshold for glucose (RTG). ${ }^{5-7}$ This threshold can be increased up to $240 \mathrm{mg} / \mathrm{dL}$ in those with T2DM. ${ }^{8}$ At PG levels exceeding the RTG, SGLT2 becomes saturated and urine glucose concentrations increase proportionately to PG levels. By inhibiting SGLT2, renal glucose reabsorption is reduced, leading to increased urine glucose excretion and a subsequent reduction in PG. ${ }^{9}$ Importantly, SGLT2 inhibition reduces PG in an insulin-independent manner, potentially mitigating the risk for hypoglycemia.

Canagliflozin is a selective inhibitor for SGLT2 that lowers the RTG to approximately $80 \mathrm{mg} / \mathrm{dL}$, increasing the urinary excretion of glucose. ${ }^{9}$ At higher doses (300 mg per day or higher), canagliflozin may also inhibit SGLT1 in the intestine and delay postprandial glucose absorption; ${ }^{10}$ doses of $100 \mathrm{mg}$ daily do not appear to have a significant affinity for the SGLT1 receptor.

Canagliflozin reaches peak plasma concentrations within 1 to 2 hours following oral administration, and steady state levels are reached in 4 to 5 days, ${ }^{11}$ it has a bioavailability of $65 \%$ and is highly protein bound (99\%), mainly to albumin.
Following single oral doses, the terminal half-life was 10.6 and 13.1 hours for canagliflozin $100 \mathrm{mg}$ and $300 \mathrm{mg}$, respectively. With continued dosing, canagliflozin reduces the RTG throughout the 24 hour dosing interval, allowing for once daily dosing. Metabolism is mainly via O-glucuronidation via uridine diphosphate glucuronosyltransferase 1A9 (UGT1A9) and uridine diphosphate glucuronosyltransferase B4 (UGT2B4) to inactive metabolites, which are renally eliminated. Cytochrome P450 (CYP) metabolism of canagliflozin is minimal, reducing the potential for drug-drug interactions. Approximately $33 \%$ of canagliflozin metabolites are renally eliminated and approximately $42 \%$ is excreted in the feces. ${ }^{11}$

\section{Clinical trials \\ Search criteria}

PubMed was searched using the term "canagliflozin" and "SGLT2" from inception to May 2013. The reference lists from identified articles were hand searched for additional relevant information. Only published trials conducted in humans were included; if studies evaluated doses other than $100 \mathrm{mg}$ and $300 \mathrm{mg}$, only the information for the US Food and Drug Administration (FDA)-approved doses was evaluated in detail and is reported in this review.

\section{Monotherapy}

The CANTATA-M (Efficacy and safety of canagliflozin monotherapy in subjects with type 2 diabetes mellitus inadequately controlled with diet and exercise) trial investigated the safety and efficacy of canagliflozin monotherapy in addition to diet and exercise in patients with T2DM (Table 1). ${ }^{12}$ Eligible patients were aged $18-80$ years and met one of the following criteria: 1) not receiving an oral antidiabetic agent (ADA) with an $\mathrm{A}_{1 \mathrm{c}}>7 \%$ but $<10 \%$ at screening (main study); or 2) on monotherapy (except thiazolidinedione) or combination therapy with metformin plus a sulfonylurea (at $<50 \%$ maximum doses) with an $\mathrm{A}_{1 \mathrm{c}}$ of $6.5-9.5 \%$ at screening; a fasting blood glucose (FBG) $<270 \mathrm{mg} / \mathrm{dL}$, and an $\mathrm{A}_{1 \mathrm{c}}$ of $>7 \%$ but $<10 \%$ after a 2 week washout period. Patients with a baseline $\mathrm{A}_{1 \mathrm{c}}>10 \%$ but $<12 \%$ and an FBG of $<350 \mathrm{mg} / \mathrm{dL} 1$ week before randomization were eligible for enrollment into the "high glycemic" cohort. Patients were excluded if they had an estimated glomerular filtration rate (eGFR) of $<50 \mathrm{~mL} / \mathrm{min} / 1.73 \mathrm{~m}^{2}$ at screening or $\mathrm{CV}$ disease, or if they were receiving any other ADA other than metformin and/or a sulfonylurea. ${ }^{12}$

The primary outcome was the change in $A_{1 c}$ from baseline to week 26 for canagliflozin versus placebo in the 
Table I Efficacy of canagliflozin in clinical trials

\begin{tabular}{|c|c|c|c|}
\hline Study & Design and intervention & Primary outcome & Secondary outcomes \\
\hline Stenlöf et al ${ }^{12}$ & $\begin{array}{l}\text { - } 26 \text { week R, DB, PC, PG } \\
\text { - Main study: can } 100 \mathrm{mg}(\mathrm{n}=195) \text {, } \\
\text { can } 300 \mathrm{mg}(\mathrm{n}=197) \text {, or pcb }(\mathrm{n}=192) \\
\text { added to diet and exercise } \\
\text { - High glycemic: can } 100 \mathrm{mg}(\mathrm{n}=47) \text { or can } \\
\\
\quad 300 \mathrm{mg}(\mathrm{n}=44) \text { added to diet and exercise }\end{array}$ & $\begin{array}{l}\text { - Reduction in } \mathrm{A}_{\mathrm{Ic}} \text { from baseline } \\
\text { - Main study (LS mean difference } \\
\text { compared to pcb): can } 100 \mathrm{mg} \text { : } \\
\text {-0.91\%; can } 300 \mathrm{mg}:-1.16 \% \\
\text { - High glycemic: can } 100 \mathrm{mg}: \\
\text {-2.13\%; can } 300 \mathrm{mg}:-2.56 \%\end{array}$ & $\begin{array}{l}\text { FBG: reduced by } 27 \mathrm{mg} / \mathrm{dL} \text { with can } 100 \mathrm{mg} \\
\text { and } 34 \mathrm{mg} / \mathrm{dL} \text { with can } 300 \mathrm{mg} \\
\text { BW: }-1.9 \mathrm{~kg} \text { with can } 100 \mathrm{mg} \text { and }-2.9 \mathrm{~kg} \\
\text { with can } 300 \mathrm{mg} \text { (LS mean difference versus } \\
\text { pcb) }\end{array}$ \\
\hline $\begin{array}{l}\text { Rosenstock } \\
\text { et } \mathrm{al}^{13}\end{array}$ & $\begin{array}{l}\text { - } 26 \text { week R, DB, PC, PG, DR study } \\
\text { - Can } 100 \mathrm{mg}(n=64) \text {, can } 300 \mathrm{mg}(\mathrm{n}=64), \\
\text { sita } 100 \mathrm{mg}(\mathrm{n}=65) \text {, or pcb }(\mathrm{n}=65) \text { added } \\
\text { to baseline metformin therapy }\end{array}$ & $\begin{array}{l}\text { - Reduction in } \mathrm{A}_{\mathrm{lc}} \text { from baseline } \\
\text { - Can } 100 \mathrm{mg}:-0.76 \% \text {; can } \\
\text { 300 mg: }-0.92 \% \text {; sita } 100 \mathrm{mg} \text { : } \\
\text {-0.74\%; pcb: }-0.22 \%\end{array}$ & $\begin{array}{l}\text { FBG: can I00 mg: }-25.2 \mathrm{mg} / \mathrm{dL} ; \text { can } 300 \mathrm{mg}: \\
-25.2 \mathrm{mg} / \mathrm{dL} \text {; sita } 100 \mathrm{mg}:-12.6 \mathrm{mg} / \mathrm{dL} ; \\
\text { pcb: } 3.6 \mathrm{mg} / \mathrm{dL} \\
\text { BW: can } 100 \mathrm{mg}:-2.6 \mathrm{~kg} \text {; can } 300 \mathrm{mg}: \\
-3.4 \mathrm{~kg} \text {; sita } 100 \mathrm{~kg}:-0.4 \mathrm{~kg} ; \text { pcb: }-0.8 \mathrm{~kg}\end{array}$ \\
\hline $\begin{array}{l}\text { Schernthaner } \\
\text { et } \mathrm{al}^{14}\end{array}$ & $\begin{array}{l}\text { - } 52 \text { week R, DB, AC, NI } \\
\text { - Can } 300 \mathrm{mg}(\mathrm{n}=378) \text {, Sita } 100 \mathrm{mg} \\
\quad(\mathrm{n}=378) \text { with metformin plus sulfonylurea }\end{array}$ & $\begin{array}{l}\text { - Reduction in } \mathrm{A}_{\mathrm{Ic}} \text { from baseline } \\
\text { - Can } 300 \mathrm{mg}:-1.03 \% \text {; Sita } \\
\text { I00 mg: }-0.66 \%\end{array}$ & $\begin{array}{l}\text { FBG: can } 300 \mathrm{mg}:-28.7 \mathrm{mg} / \mathrm{dL} \text {; Sita } 100 \mathrm{mg}: \\
-2.2 \mathrm{mg} / \mathrm{dL} \\
\text { BW: can } 300 \mathrm{mg}:-2.6 \mathrm{~kg} \text {; sita } 100 \mathrm{mg}:-0.1 \mathrm{~kg}\end{array}$ \\
\hline Devineni et $\mathrm{al}^{15}$ & $\begin{array}{l}\text { - } 28 \text { day R, DB, PC } \\
\text { - Can } 100 \mathrm{mg}(\mathrm{n}=10) \text {, can } 600 \mathrm{mg}(\mathrm{n}=10) \text {, } \\
\quad \text { or } \mathrm{pcb}(\mathrm{n}=9) \text { with insulin therapy }\end{array}$ & $\begin{array}{l}\text { - Reduction in } \mathrm{A}_{\mathrm{Ic}} \text { from baseline } \\
\text { - Can } 100 \mathrm{mg}:-0.37 \% \%^{\wedge} \text { can } \\
\quad 600 \mathrm{mg}:-0.55 \%^{\wedge}\end{array}$ & $\begin{array}{l}\text { FBG: can } 100 \mathrm{mg}:-2.37 \mathrm{mmol} / \mathrm{L} ;{ }^{\wedge} \text { can } 600 \mathrm{mg}: \\
-2.48 \mathrm{mmol} / \mathrm{L}^{\wedge} \\
\text { BW: can } 100 \mathrm{mg}:-0.68 \mathrm{~kg} ; \text { can } \\
600 \mathrm{mg}:-1.24 \mathrm{~kg}\end{array}$ \\
\hline Yale et al ${ }^{16}$ & $\begin{array}{l}\text { - } 26 \text { week } R, D B, P C \text { study in patients } \\
\text { with stage } 3 \text { CKD } \\
\text { - Can } 100 \mathrm{mg}(n=90) \text {, can } 300 \mathrm{mg}(\mathrm{n}=89) \text {, } \\
\text { or pcb }(\mathrm{n}=90) \text { in addition to background } \\
\text { therapy }\end{array}$ & $\begin{array}{l}\text { - Reduction in } \mathrm{A}_{\mathrm{Ic}} \text { from baseline } \\
\text { - Can I00: }-0.37 \% \text {; can } 300 \mathrm{mg} \text { : } \\
\text {-0.44\%; pcb: }-0.03 \%\end{array}$ & $\begin{array}{l}\text { FBG: not statistically different between } \\
\text { groups } \\
\text { BW: can 100: }-1.4 \mathrm{~kg} \text {; can } 300 \mathrm{mg}:-1.6 \mathrm{~kg} \text {; } \\
\text { pcb: } 0.2 \mathrm{~kg}\end{array}$ \\
\hline Bode et al ${ }^{17}$ & $\begin{array}{l}\text { - } 26 \text { week R, DB, PC study in patients } \\
\text { aged } 55-80 \text { years } \\
\text { - Can } 100 \mathrm{mg} \text {, can } 300 \mathrm{mg} \text {, or pcb in } \\
\text { addition to background therapy }\end{array}$ & $\begin{array}{l}\text { - Reduction in } \mathrm{A}_{\mathrm{Ic}} \text { from baseline } \\
\text { - Can 100: }-0.60 \% \text {; can } 300 \mathrm{mg} \text { : } \\
\text {-0.73\%; pcb: }-0.03 \%\end{array}$ & $\begin{array}{l}\text { FBG: can } 100 \text { mg: }-25.5 \text { mg/dL; can } 300 \text { mg: } \\
27.7 \mathrm{mg} / \mathrm{dL} \\
\text { BW: can } 100 \mathrm{mg}:-2.1 \mathrm{~kg} \text {; can } 300 \mathrm{mg}:-2.7 \mathrm{~kg}\end{array}$ \\
\hline
\end{tabular}

Note: ^Compared to placebo.

Abbreviations: $A C$, active control; $A_{1 c}$, hemoglobin $A_{1 c}$; BW, body weight; Can/can, canagliflozin; CKD, chronic kidney disease; DB, double-blind; DR, dose ranging; FBG, fasting blood glucose; LS, least squares, NI, noninferiority; PC, placebo-controlled; pcb, placebo; PG, parallel group; R, randomized; Sita/sita, sitagliptin.

modified intent-to-treat (mITT) population, which included all patients who received at least one dose of study medication. Secondary outcomes included the proportion of patients achieving an $\mathrm{A}_{1 \mathrm{c}}<7 \%$ and changes from baseline in $\mathrm{FBG}$, BP, high-density lipoprotein (HDL), triglycerides (TG), and body weight. Comparisons between treatment regimens were performed using the least squares (LS) mean method. To have $90 \%$ power to detect a between-group difference of $0.5 \%$, at least 85 patients per group were needed. However, for $\mathrm{AE}$ tracking purposes, 150 patients per group were targeted for enrollment. ${ }^{12}$

Those patients not receiving an ADA at screening underwent a 2 week placebo run-in period followed by randomization, whereas those receiving an ADA at screening underwent an 8 week washout and placebo run-in period. Patients in the main study were randomized in a double-blind fashion at a 1:1:1 ratio to receive canagliflozin $100 \mathrm{mg}$ daily $(\mathrm{n}=195)$, canagliflozin $300 \mathrm{mg}$ daily $(\mathrm{n}=197)$, or placebo $(n=192)$ for 26 weeks. The high glycemic cohort consisted of 47 patients randomized to receive canagliflozin $100 \mathrm{mg}$ daily and 44 patients randomized to canagliflozin $300 \mathrm{mg}$ daily, both for 26 weeks; there was no placebo group. Metformin was used as a glycemic rescue for elevated FBG values in both cohorts.

At randomization, the mean age in the main study was 55.4 years; $44 \%$ of patients were male, $67.6 \%$ were White, and $7 \%$ were Black. The mean $\mathrm{A}_{1 \mathrm{c}}$ was $8 \%$, the mean $\mathrm{FBG}$ was $171 \mathrm{mg} / \mathrm{dL}$, and the mean body weight and body mass index (BMI) were $86.8 \mathrm{~kg}$ and $30.4 \mathrm{~kg} / \mathrm{m}^{2}$, respectively. The high glycemic cohort had a mean age of 49.3 years; $54 \%$ of patients were male, $60.4 \%$ were White, and $4.4 \%$ were Black. The mean $\mathrm{A}_{1 \mathrm{c}}$ and FBG were $10.6 \%$ and $241 \mathrm{mg} / \mathrm{dL}$, respectively, and patients weighed an average of $82.5 \mathrm{~kg}$ and had a BMI of $30.5 \mathrm{~kg} / \mathrm{m}^{2}$. In the main study, $48 \%$ of patients were receiving an ADA at screening, whereas 23\% of the subjects in the high glycemic cohort were receiving an ADA.

In all, 584 patients in the main study were included for analysis (mITT population). After 26 weeks of treatment, canagliflozin $100 \mathrm{mg}$ and $300 \mathrm{mg}$ reduced the baseline $\mathrm{A}_{1 \mathrm{c}}$ by $0.77 \%$ and $1.03 \%$, respectively, which led to an LS mean difference of $-0.91 \%$ and $-1.16 \%$ compared with 
placebo $(P<0.001$ for both doses) (Table 1$)$. In the high glycemic cohort, the baseline $\mathrm{A}_{1 \mathrm{c}}$ was reduced by $2.13 \%$ with canagliflozin $100 \mathrm{mg}$ and $2.56 \%$ with canagliflozin $300 \mathrm{mg}$ in the 91 subjects who were included in the analysis. In both cohorts, similar reductions in $\mathrm{A}_{1 \mathrm{c}}$ were seen regardless of current use or history of treatment with an ADA at baseline.

Secondary outcomes were also improved with canagliflozin compared with placebo, including a higher proportion of patients reaching an $\mathrm{A}_{1 \mathrm{c}}<7 \%$, larger reductions in $\mathrm{FBG}$ (mean decrease of $27 \mathrm{mg} / \mathrm{dL}$ with canagliflozin $100 \mathrm{mg}$ and $34 \mathrm{mg} / \mathrm{dL}$ with canagliflozin $300 \mathrm{mg}$ ), and a LS mean difference in body weight of $-1.9 \mathrm{~kg}$ and $-2.9 \mathrm{~kg}$ for canagliflozin $100 \mathrm{mg}$ and $300 \mathrm{mg}$, respectively. Systolic BP and HDL were also improved with canagliflozin, whereas TG and diastolic BP were not statistically different compared to placebo. LDL was marginally increased by $2 \%$ and $6.1 \%$ in those receiving canagliflozin $100 \mathrm{mg}$ and $300 \mathrm{mg}$, respectively, compared to placebo. Fewer patients receiving canagliflozin required rescue therapy with metformin $(2.6 \%$ and $2.0 \%$ with canagliflozin $100 \mathrm{mg}$ and $300 \mathrm{mg}$, respectively) compared with those randomized to receive placebo (22.7\%).

AEs considered to be related to study medication occurred in $9.4 \%$ of patients receiving placebo; $17.4 \%$ of those receiving canagliflozin $100 \mathrm{mg}$ daily; and in $25.4 \%$ in those receiving canagliflozin $300 \mathrm{mg}$ daily. Only ten patients receiving canagliflozin $(2.6 \%)$ discontinued the study due to AEs compared to two patients receiving placebo (1\%). Importantly, genital mycotic infections were seen in a higher percent of both males $(4.1 \%)$ and females $(8.1 \%)$ receiving canagliflozin compared with those receiving placebo (no cases in males, but in 3.9\% of females). However, most infections were mild to moderate in severity and were effectively treated with traditional oral or topical treatments; a mild increase in the risk for urinary tract infections was also noted. No cases of severe hypoglycemia were noted; only $3.6 \%, 3 \%$, and $2.6 \%$ of patients receiving canagliflozin $100 \mathrm{mg}, 300 \mathrm{mg}$, or placebo, respectively, experienced mild hypoglycemia. Increases in blood urea nitrogen (BUN) and serum creatinine $(\mathrm{SCr})$ were also noted in those receiving canagliflozin.

\section{Combination therapy: canagliflozin versus sitagliptin}

A 12 week randomized, double-blind, placebo-controlled, parallel group dose-ranging study evaluated the safety and efficacy of canagliflozin in patients with T2DM who were receiving stable doses of metformin. ${ }^{13}$ Eligible patients included those receiving stable metformin monotherapy for $>3$ months at a dose of $>1,500 \mathrm{mg} /$ day who had a baseline $\mathrm{A}_{1 \mathrm{c}}$ of $>7 \%$ but $<10.5 \%$; serum creatinine was also required to be $<1.4 \mathrm{mg} / \mathrm{dL}$ for females and $<1.5 \mathrm{mg} / \mathrm{dL}$ for males. No specific exclusion criteria were provided. ${ }^{13}$

The mean age of the study patients was 52.9 years and $52 \%$ were male; no information regarding race or ethnicity was provided. The baseline $\mathrm{A}_{1 \mathrm{c}}$ ranged from $7.6 \%-8 \%$ across the treatment groups, and the average FBG was $162 \mathrm{mg} / \mathrm{dL}$; the mean bodyweight and BMI were $87.1 \mathrm{~kg}$ and $31.5 \mathrm{~kg} / \mathrm{m}^{2}$, respectively. The average metformin dose was $1,890 \mathrm{mg} /$ day, and the mean duration of diabetes was 6 years.

After a 3-4 week pretreatment screening phase, patients were randomized to receive canagliflozin once daily at a dose of $50 \mathrm{mg}(\mathrm{n}=64), 100 \mathrm{mg}(\mathrm{n}=64), 200 \mathrm{mg}(\mathrm{n}=65)$, or $300 \mathrm{mg}(\mathrm{n}=64)$, canagliflozin $300 \mathrm{mg}$ twice daily (BID) $(n=64)$, sitagliptin $100 \mathrm{mg}$ daily $(n=65)$, or placebo $(n=65)$ for 12 weeks, in addition to baseline metformin therapy. The Sitagliptin arm was included to provide a benchmark for clinical efficacy and was not compared statistically to placebo or any dose of canagliflozin. The primary outcome was the change in $\mathrm{A}_{1 \mathrm{c}}$ from baseline after 12 weeks of treatment; secondary outcomes included changes in weight and FBG, urinary glucose-to-creatinine ratio, and assessment of betacell function. Outcomes were analyzed in the ITT population, which included 451 patients. Results for the $100 \mathrm{mg}$ and $300 \mathrm{mg}$ once daily canagliflozin doses will be emphasized hereinafter as they represent the currently approved doses.

After 12 weeks of treatment, canagliflozin $100 \mathrm{mg}$ and $300 \mathrm{mg}$ significantly reduced the baseline $\mathrm{A}_{1 \mathrm{c}}$ by $0.76 \%$ and $0.92 \%$, respectively, compared with a $0.2 \%$ reduction with placebo $(P<0.001$ for both doses compared to placebo) (Table 1 ). Sitaglipitin $100 \mathrm{mg}$ daily produced a $0.74 \%$ reduction in the $A_{1 \mathrm{c}}$, whereas canagliflozin $100 \mathrm{mg}$ and $300 \mathrm{mg}$ reduced the baseline body weight by $2.6 \mathrm{~kg}$ and $3.4 \mathrm{~kg}$, respectively, and both doses reduced FBG by $25.2 \mathrm{mg} / \mathrm{dL}$. The weight loss produced by canagliflozin was progressive throughout the study and did not appear to plateau by study end. Urinary glucose excretion was increased with canagliflozin $100 \mathrm{mg}$ and $300 \mathrm{mg}$ to $51.5 \mathrm{mg} / \mathrm{dL}$ and $49.4 \mathrm{mg} / \mathrm{dL}$, respectively; and the RTG decreased to $80 \mathrm{mg} / \mathrm{dL}$ with canagliflozin $300 \mathrm{mg}$ daily. Treatment with canagliflozin also improved HDL and TG but caused a minor increase in LDL in only those receiving BID canagliflozin (specific increase not reported). Beta-cell function was also improved in both canagliflozin and sitagliptin compared with placebo.

The incidence of AEs was similar across treatment groups, and only eleven patients discontinued the study early due to 
an AE; nine of these subjects were randomized to receive canagliflozin $(2.8 \%)$. Events that occurred in more than ten patients included urinary tract infections (UTIs), headache, vulvovaginal mycotic infections, nausea, nasopharyngitis, diarrhea, and pollakiuria. The risk for UTI was not increased with canagliflozin treatment, although the risk for genital mycotic infections in females was increased, most commonly vulvovaginal candidiasis. Only one event was observed in females receiving placebo (3\%) compared with 28 events $(18 \%)$ in females receiving canagliflozin. However, these infections were generally mild in severity and responded to topical and/or oral treatments. Importantly, there were no cases of severe hypoglycemia and only eleven cases of symptomatic hypoglycemia, seven of which occurred in those receiving canagliflozin $(2.2 \%)$. Important limitations to consider include the short study duration (12 weeks) and small sample size, as only 128 patients received a currently approved dose of canagliflozin.

It is not uncommon for T2DM in many patients to progress to the point of needing multiple medications to reach therapeutic goals. Schernthaner et $\mathrm{a}^{14}$ studied canagliflozin in a 52 week, randomized, noninferiority, double-blind Phase III study to determine the efficacy of using canagliflozin in patients taking metformin and a sulfonylurea compared to sitagliptin in uncontrolled patients.

To be eligible, participants must have been taking $>1,500 \mathrm{mg}$ of metformin daily and a sulfonylurea dose of at least half the maximum labeled dose. Participants were also required to have an $\mathrm{A}_{1 \mathrm{c}}$ between $7.0 \%$ and $10.5 \%$. Subjects were excluded if they presented with any of the following: type 1 diabetes; CV disease or uncontrolled hypertension; receiving insulin or any other oral hypoglycemic therapy other than metformin or a sulfonylurea; eGFR $<55 \mathrm{~mL} / \mathrm{min} / 1.73 \mathrm{~m}^{2}\left(60 \mathrm{~mL} / \mathrm{min} / 1.73 \mathrm{~m}^{2}\right.$ based on restriction of metformin use), serum creatinine of $\geq 1.5 \mathrm{mg} / \mathrm{dL}$ (men) or $\geq 1.4 \mathrm{mg} / \mathrm{dL}$ (women); or repeated FBG values $>300 \mathrm{mg} / \mathrm{dL}$.

The study included 755 participants who were randomized to receive either canagliflozin $300 \mathrm{mg}$ daily $(\mathrm{n}=378)$ or sitagliptin $100 \mathrm{mg}$ daily $(\mathrm{n}=378)$ in addition to their baseline therapy. Subjects first underwent a 2 week single blinded placebo run-in period, followed by 52 weeks of treatment with study medication and a 4 week follow-up period. Once enrolled in the study, participants presenting with an FBG of at least $270 \mathrm{mg} / \mathrm{dL}$ between day 1 and week $6,240 \mathrm{mg} / \mathrm{dL}$ between week 6 and week 12, or $200 \mathrm{mg} / \mathrm{dL}$ between week 12 and week 26 were removed from the study. Patients with an $A_{1 c} \geq 8.0 \%$ after week 26 were also removed from the study, as were those who met the initial exclusion criteria regarding serum creatinine or eGFR or developed a contraindication to metformin.

After 52 weeks of treatment, 210 subjects in the canagliflozin $300 \mathrm{mg}$ daily group and 254 subjects in the sitagliptin $100 \mathrm{mg}$ daily group completed the study; however, all patients were included in the ITT analysis. Participants in each arm had similar baseline characteristics, with an average age of 56.7 years, average $\mathrm{A}_{1 \mathrm{c}}$ of $8.1 \%$, and a duration of diabetes of $>9$ years. A majority of the participants, $64.2 \%$, were White; only $11.7 \%$ of the participants identifying themselves as Black or African American.

The primary endpoint, change in $\mathrm{A}_{1 \mathrm{c}}$ from baseline at week 52 , was found to be $-1.03 \%$ and $-0.66 \%$ in the canagliflozin $300 \mathrm{mg}$ daily and sitagliptin $100 \mathrm{mg}$ daily groups, respectively, with a difference of $-0.37 \%$ (95\% confidence interval [CI], -0.50 to -0.25 ) (Table 1 ). The authors noted that this result not only met the criteria for noninferiority but also indicated that canagliflozin $300 \mathrm{mg}$ daily may actually be superior to sitagliptin $100 \mathrm{mg}$ daily in their study subjects. Canagliflozin and sitagliptin reduced FBG by $28.7 \mathrm{mg} / \mathrm{dL}$ and $2.2 \mathrm{mg} / \mathrm{dL}$, respectively, and $47.6 \%$ of the canagliflozin $300 \mathrm{mg}$ daily group versus $35.3 \%$ of the participants in the sitagliptin $100 \mathrm{mg}$ daily group reached an $\mathrm{A}_{1 \mathrm{c}}$ level of $<7 \%$. A higher rate of discontinuation was seen in the sitagliptin group $(22.5 \%)$ compared with the canagliflozin group $(10.6 \%)$ when those receiving sitagliptin met withdrawal criteria due to poor glycemic control. This further indicates that participants appeared to be better controlled with canagliflozin $300 \mathrm{mg}$ daily than with sitagliptin $100 \mathrm{mg}$ daily.

Along with the reduction in glucose, a significant reduction in body weight, systolic BP, and diastolic BP was seen with canagliflozin relative to sitagliptin at $-2.6 \mathrm{~kg}$ versus $-0.1 \mathrm{~kg}(P<0.001),-5.1 \mathrm{mmHg}$ versus $0.9 \mathrm{mmHg}$ $(P<0.001)$, and $-3.0 \mathrm{mmHg}$ versus $-0.3 \mathrm{mmHg}$ (difference of $-2.7 \mathrm{mmHg}, 95 \% \mathrm{CI},-3.8$ to -1.7$)$. Also, both HDL and LDL were increased in the canagliflozin group compared with the sitagliptin group, by $7.6 \%$ versus $0.6 \%$ (difference of 7\%, 95\% CI 4.6-9.3) and $11.7 \%$ versus 5.2\% (difference of $6.4 \%, 95 \%$ CI $1.7-11.2$ ).

Overall study discontinuations in the canagliflozin and sitagliptin groups were reported as 168 and 123, respectively. The incidence of any AE appeared to be fairly similar between the two groups, with 293 and 289 patients reporting an AE in the canagliflozin and sitagliptin group, respectively; however, canagliflozin was associated with a higher incidence of genital mycotic infections compared with sitagliptin (45 versus eight cases). There was only one reported discontinuation 
resulting from mycotic infection in the canagliflozin group. The incidence of UTIs was similar in each group, as were increases in urinary frequency. Any other AE reported by less than $2 \%$ of the participants was considered to be negligible by the authors.

The authors concluded that the addition of canagliflozin $300 \mathrm{mg}$ daily can significantly improve glycemic control, reduce weight, and reduce systolic $\mathrm{BP}$ when added to oral therapy with metformin and a sulfonylurea. Important limitations were the short study duration and the unknown efficacy of canagliflozin if it is added to other oral ADAs besides metformin and a sulfonylurea.

\section{Canagliflozin combined with insulin}

Because of its unique mechanism of action, the use of canagliflozin may provide additional benefit when used in combination with insulin. In a small, randomized, doubleblind, placebo-controlled study, Devineni et al ${ }^{15}$ enrolled 29 patients with T2DM currently not controlled on insulin and one or no ADA. Subjects were randomized to either canagliflozin $100 \mathrm{mg}$ daily $(\mathrm{n}=10)$ or placebo $(\mathrm{n}=5)$ in cohort 1 or canagliflozin $300 \mathrm{mg}$ BID $(n=10)$ or placebo $(n=4)$ in cohort 2 . Subjects were followed weekly while participating in this study.

Study subjects were between the ages of 18 and 65 years, diagnosed with T2DM for $\geq 6$ months, were on stable insulin therapy for $\geq 2$ weeks, and had a BMI of $25-35 \mathrm{~kg} / \mathrm{m}^{2}$, an FBG 59-270 mg/dL, an $\mathrm{A}_{1 \mathrm{c}} 7 \%-5 \%$, and a serum creatinine of $<1.5 \mathrm{mg} / \mathrm{dL}$ for men and $<4 \mathrm{mg} / \mathrm{dL}$ for women. Potential subjects were excluded if they had history of $\mathrm{CV}$, hematologic, respiratory, renal, or gastrointestinal disease. Also excluded were those with type 1 diabetes, those who had received an insulin infusion within the past 3 months, those who had a history of diabetic ketoacidosis, and women at risk of becoming pregnant.

The authors reported that the baseline characteristics were similar between groups; however, statistical analysis was not conducted and/or not reported. Key characteristics for placebo, canagliflozin $100 \mathrm{mg}$, and canagliflozin $300 \mathrm{mg}$ BID groups, respectively, are as follows; average age 52.8, 50.5, and 47.2 years; average weight of $95.1,107.8$, and $94.1 \mathrm{~kg}$; average $\mathrm{A}_{1 \mathrm{c}}$ of $8.3 \%, 8.45 \%$, and $8.4 \%$; average total daily insulin use of $38.4,114.6$, and 51.4 units.

At the end of the 28 days, a significant decrease in $\mathrm{A}_{1 \mathrm{c}}$ of $0.37 \%$ was observed in the canagliflozin $100 \mathrm{mg}$ group $(P<0.05)$ and $0.55 \%$ in the canagliflozin $300 \mathrm{mg}$ BID group $(P<0.05)$ compared with placebo (Table 1$)$. This correlated to a reduction in $\mathrm{FBG}$ of $42.7 \mathrm{mg} / \mathrm{dL}$ and $44.6 \mathrm{mg} / \mathrm{dL}$ in the canagliflozin $100 \mathrm{mg}$ daily and $300 \mathrm{mg}$ BID groups, respectively, compared with placebo ( $P<0.05$ for both groups). A reduction in 24 hour $P G$ levels along with an increase in urinary glucose excretion (67.20 g/day and $153.60 \mathrm{~g} /$ day) was also seen in the canagliflozin $100 \mathrm{mg}$ and $300 \mathrm{mg}$ BID groups, respectively, compared with placebo $(P<0.05)$. Body weight decreased by $0.68 \mathrm{~kg}$ in the canagliflozin $100 \mathrm{mg}$ group and by $1.24 \mathrm{~kg}$ in the canagliflozin $300 \mathrm{mg}$ BID group compared with placebo; only the decrease in body weight for the $300 \mathrm{mg}$ BID group reached statistical significance.

All groups had a similar overall rate of AEs reported. The canagliflozin $300 \mathrm{mg}$ BID group did report a higher incidence of headaches $(n=6)$ when compared with both canagliflozin $100 \mathrm{mg}$ daily $(\mathrm{n}=3)$ and placebo $(\mathrm{n}=2)$. Patients taking canagliflozin did see a clinically insignificant increase in serum creatinine compared with placebo, which returned to baseline once canagliflozin was discontinued. All other laboratory markers reported in the study appeared to show no clinically significant change in any group other than changes in urinary urate excretion, which was reduced with canagliflozin.

Based on this study, it appears that canagliflozin may be beneficial in patients with T2DM who are uncontrolled with insulin therapy. Because of the size of this study and the short follow-up time, more data will be needed to fully assess the potential benefits and risk with the combination of canagliflozin and insulin.

\section{Safety in specific populations}

Yale et $\mathrm{al}^{16}$ conducted a study with the objective of determining the safety and efficacy of canagliflozin in subjects diagnosed with stage 3 chronic kidney disease (CKD) (Table 2). This randomized double-blind, placebo-controlled Phase III study included 269 subjects randomized to receive canagliflozin $100 \mathrm{mg}$ daily, canagliflozin $300 \mathrm{mg}$ daily, or placebo for 26 weeks. Results of a 26 week double-blind extension period were planned to be reported separately. Patients may have also been initiated on glycemic rescue therapy either by an up-titration of current medications or with the addition of other oral medications if FBG became $>270 \mathrm{mg} / \mathrm{dL}$ during week 1 to $6,>240 \mathrm{mg} / \mathrm{dL}$ during week 6 to week 12 , or $>200 \mathrm{mg} / \mathrm{dL}$ during week 12 to week 26 .

Eligible patients had to have stage $3 \mathrm{CKD}$ (eGFR $\geq 30$ and $<50 \mathrm{~mL} / \mathrm{min} / 1.73 \mathrm{~m}^{2}$ ) and T2DM that was inadequately controlled $\left(\mathrm{A}_{1 \mathrm{c}} \geq 7.0 \%\right.$ and $\left.\leq 10.5 \%\right)$, and either be receiving a stable oral hypoglycemic regimen (monotherapy or combination therapy) or no treatment at all. Potential participants were excluded if they had recurrent FBG $>270 \mathrm{mg} / \mathrm{dL}$ during the pretreatment phase, were receiving immunosuppressant 
Table 2 Safety in specific populations

\begin{tabular}{|c|c|c|c|}
\hline Study & Design and intervention & Primary outcome & Adverse drug events \\
\hline Yale et $\mathrm{al}^{16}$ & $\begin{aligned} & \text { - } 26 \text { week R, DB, PC } \\
& \text { - } \text { stage } 3 \text { chronic kidney disease (CKD) } \\
&\left(\text { eGFR } \geq 30 \text { and }<50 \mathrm{~mL} / \mathrm{min} / \mathrm{l} .73 \mathrm{~m}^{2}\right) \\
& \text { - can } 100 \mathrm{mg}(\mathrm{n}=90), \text { can } 300 \mathrm{mg} \\
& \quad(\mathrm{n}=89), \text { or } \mathrm{pcb}(\mathrm{n}=90)\end{aligned}$ & $\begin{array}{l}\text { - Reduction in } A_{1 c} \text { from baseline } \\
\text { - LS mean difference compared to } \\
\text { pcb: can } 100 \mathrm{mg}: 0.3 \%(P<0.05) \text {; } \\
\text { can } 300 \mathrm{mg}: 0.4 \%(P<0.00 \mathrm{I})\end{array}$ & $\begin{array}{l}\text { - Mycotic infections: can } 100 \mathrm{mg}(\mathrm{n}=2) \text {; } \\
\text { can } 300 \mathrm{mg}(\mathrm{n}=2) \text {; pcb }(\mathrm{n}=0) \\
\text { - Change in eGFR: can I00 mg: }-9.1 \% \text {; } \\
\text { can } 300 \mathrm{mg:}-10.1 \% \text {; pcb; }-4.5 \% \\
\text { - Change in BUN: can I00 mg: }+12.1 \% \text {; } \\
\text { can } 300 \mathrm{mg}:+12.5 \% ; \mathrm{pcb}:+4.9 \%\end{array}$ \\
\hline Bode et $\mathrm{al}^{17}$ & $\begin{array}{l}\text { - } 26 \text { week R, DB, PC } \\
\text { - Average age of } 63.6 \text { years } \\
\text { - Can I00 mg }(n=24 I) \text {, can } 300 \mathrm{mg} \\
\quad(n=236) \text {, or } \mathrm{pcb}(n=237)\end{array}$ & $\begin{array}{l}\text { - Reduction in } \mathrm{A}_{\mathrm{Ic}} \text { from baseline } \\
\text { - Compared to pcb: Can } 100 \mathrm{mg} \text { : } \\
\text {-0.57\%; can } 300 \mathrm{mg}:-0.7 \%\end{array}$ & 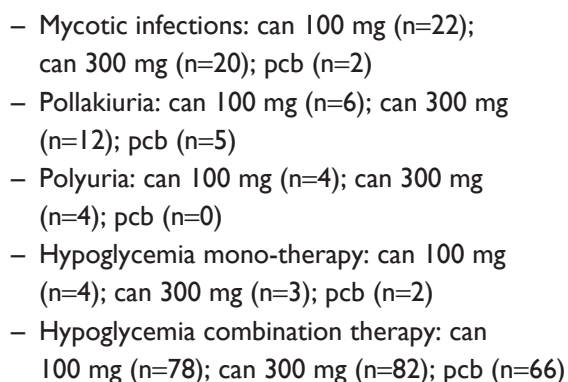 \\
\hline
\end{tabular}

Abbreviations: R, randomized; DB, double-blind; PC, placebo-controlled; eGFR, estimated glomerular filtration rate; can, canagliflozin; pcb, placebo; $A_{1 c^{\prime}}$, hemoglobin $A_{1 c^{\prime}}$; LS, least squares; BUN, blood urea nitrogen.

medications, had a history of previous transplant, currently on dialysis, previous or current $\mathrm{CV}$ issues, or had a cerebrovascular incident within 3 months of screening.

Initially, 269 patients were randomized and 234 subjects completed the study with 77,75 , and 82 patients in the placebo, canagliflozin $100 \mathrm{mg}$ daily, and canagliflozin $300 \mathrm{mg}$ daily groups, respectively. Baseline characteristics of these subjects included an average age of $68.5 \pm 8.3$ years, and average $A_{1 c}$ of $8.0 \% \pm 0.9 \%$, an average FBG of $164.0 \pm 49.6 \mathrm{mg} / \mathrm{dL}$, an average body weight of $91.2 \pm 18.0 \mathrm{~kg}$, and an average eGFR of $39.4 \pm 6.9 \mathrm{~mL} / \mathrm{min}$. The authors did not report any significant differences in these baseline characteristics between treatment groups.

After 26 weeks of treatment, canagliflozin $100 \mathrm{mg}$ and $300 \mathrm{mg}$ led to an LS mean difference in the $\mathrm{A}_{1 \mathrm{c}}$ of $0.3 \%$ $(P<0.05)$ and $0.4 \%(P<0.001)$, respectively, compared to placebo (Table 1). A higher percentage of subjects reached an $\mathrm{A}_{1 \mathrm{c}}<7 \%$ in the canagliflozin $300 \mathrm{mg}$ group (32.6\%) and canagliflozin $100 \mathrm{mg}$ group $(27.3 \%)$ compared with the placebo group (17.2\%). This correlated with a slight reduction in FBG values in all groups, but the difference was not statistically significant.

Treatment with canagliflozin also resulted in a significant reduction in body weight when compared with placebo, reducing body weight by $1.2 \%$ and $1.5 \%$ in the canagliflozin $100 \mathrm{mg}$ and $300 \mathrm{mg}$ groups, respectively, whereas body weight increased by $0.3 \%$ in the placebo group. Systolic BP was the only other endpoint found to be significantly reduced compared with placebo, reduced by $5.7 \mathrm{mmHg}$ and $6.1 \mathrm{mmHg}$ in the canagliflozin $100 \mathrm{mg}$ and $300 \mathrm{mg}$ groups, respectively. The authors did not find any significant difference in diastolic BP, TG, LDL, or HDL cholesterol between groups.

The total number of AEs reported was not significantly different between groups. A higher incidence of genital mycotic infections was seen in the canagliflozin $100 \mathrm{mg}$ and $300 \mathrm{mg}$ groups compared with placebo $(2,2$, and 0 cases, respectively). There was a decrease in eGFR seen in all groups but was slightly higher in the canagliflozin $100 \mathrm{mg}$ and $300 \mathrm{mg}$ groups compared with placebo $(-9.1 \%,-10.1 \%$, and $-4.5 \%$, respectively). An increase in blood urea nitrogen was also seen in all groups: $12.1 \%, 12.5 \%$, and $4.9 \%$ in the canagliflozin $100 \mathrm{mg}, 300 \mathrm{mg}$, and placebo groups, respectively.

It appears that canagliflozin can still be an effective treatment option in a population with an eGFR of $30-50 \mathrm{~mL} / \mathrm{min}$. However, the $\mathrm{A}_{1 \mathrm{c}}$ lowering effects may be diminished in this population and should be taken into consideration when its use is considered in the stage $3 \mathrm{CKD}$ patient population.

Bode et al ${ }^{17}$ looked at the use of canagliflozin in an elderly population (ages 55-80 years) with T2DM uncontrolled by their current glucose-lowering regimen. This regimen could include any oral hypoglycemic agent or injectable treatment (including insulin). This randomized double-blind Phase III trial was completed over 26 weeks and is currently being followed with a 78 week extension period. Patients were randomized to receive canagliflozin $100 \mathrm{mg}$ daily, $300 \mathrm{mg}$ daily, or placebo.

Subjects included had an $\mathrm{A}_{1 \mathrm{c}} 7 \%-10 \%$ at baseline, were receiving a stable T2DM treatment regimen or receiving 
no treatment, had a BMI $20-40 \mathrm{~kg} / \mathrm{m}^{2}$, and had an FBG $110-270 \mathrm{mg} / \mathrm{dL}$. Subjects were excluded if they had a history of cardiovascular disease, uncontrolled hypertension, an eGFR $<50 \mathrm{~mL} / \mathrm{min}$, or had any renal condition that established a contraindication to metformin. This study also allowed for an up-titration or addition of medications if further glucose control was needed after initiation of study therapy.

Baseline characteristics were similar between study groups, which consisted of an average age of 63.6 years, with $38.2 \%$ of the subjects over 65 years and $6.4 \%$ of the patients over 75 years. The average baseline $A_{1 c}$ was $7.7 \%$; the average duration of T2DM was 11.7 years; and the average eGFR was $77.5 \mathrm{~mL} / \mathrm{min}$.

After 26 weeks of treatment, canagliflozin $100 \mathrm{mg}$ and $300 \mathrm{mg}$ reduced the $\mathrm{A}_{1 \mathrm{c}}$ by $0.57 \%$ and $0.7 \%$, respectively, compared with placebo $(P<0.001$ for both doses) (Table 2$)$. The percent of subjects reaching $\mathrm{A}_{1 \mathrm{c}}$ of $<7.0 \%$ was $47.7 \%, 58.8 \%$, and $28.0 \%$ in the canagliflozin $100 \mathrm{mg}, 300 \mathrm{mg}$, and placebo groups, respectively. FBG also was reduced by $25.5 \mathrm{mg} / \mathrm{dL}$ in the canagliflozin $100 \mathrm{mg}$ and $27.7 \mathrm{mg} / \mathrm{dL}$ in the $300 \mathrm{mg}$ group compared with placebo $(P<0.001)$. It was noted that those with a higher baseline $\mathrm{A}_{1 \mathrm{c}}$ had a larger reduction in $\mathrm{A}_{1 \mathrm{c}}$ at the end of the study in both of the canagliflozin groups.

Canagliflozin also led to a significant reduction in body weight $(2.1 \mathrm{~kg}$ and $2.7 \mathrm{~kg}$ decrease in the canagliflozin $100 \mathrm{mg}$ and $300 \mathrm{mg}$ groups, respectively) when compared with placebo $(P<0.001)$. As seen in previous studies, a reduction in both systolic and diastolic BP was noted in those receiving canagliflozin compared of placebo. Modest improvements in the lipid panel were also noted.

Rates of any AE were similar between the canagliflozin $100 \mathrm{mg}$ group and placebo at 174 incidents each, but were slightly higher in the canagliflozin $300 \mathrm{mg}$ group, with 184 incidents reported. A higher rate of mycotic infections was seen in the canagliflozin $100 \mathrm{mg}$ and $300 \mathrm{mg}$ groups compared to placebo with 22, 20, and 2 events, respectively, being reported. Pollakiuria was reported in five, six, and 12 cases and polyuria was observed in zero, four, and four subjects in the placebo, canagliflozin $100 \mathrm{mg}$, and canagliflozin $300 \mathrm{mg}$ groups, respectively. Discontinuation due to any $\mathrm{AE}$ occurred in ten patients receiving placebo, five receiving canagliflozin $100 \mathrm{mg}$ daily, and in 17 receiving canagliflozin $300 \mathrm{mg}$ daily. As expected, hypoglycemia was seen more often in participants on multiple ADAs, including a slightly higher incidence in the canagliflozin $100 \mathrm{mg}$ and $300 \mathrm{mg}$ compared with placebo at 66, 76, and 82 events, respectively. There were no clinically significant changes in laboratory markers between study groups.
Based on this trial, canagliflozin may be a reasonable option for elderly patients without cardiovascular disease. Canagliflozin was shown to be efficacious and was fairly well tolerated in this population. Further studies will be needed to assess the use of canagliflozin in this population with known cardiovascular disease.

\section{Canagliflozin AEs}

Despite canagliflozin's efficacy in lowering $\mathrm{A}_{1 \mathrm{c}}$, it is associated with a low incidence of hypoglycemia; no cases of severe hypoglycemia were reported in the clinical trials. This low risk for hypoglycemia is likely related to the ability of canagliflozin to lower the RTG to approximately $80 \mathrm{mg} / \mathrm{dL}$, which is higher than the cutoff of $70 \mathrm{mg} / \mathrm{dL}$ that is associated with hypoglycemia. If the PG falls below $80 \mathrm{mg} / \mathrm{dL}$, then renal reabsorption of glucose mediated by SGLT2 can occur to attenuate further decreases in PG. Accordingly, rates of hypoglycemia were generally similar for both the canagliflozin and placebo groups in clinical trials. ${ }^{11}$

Canagliflozin most notably increases risk for genital mycotic infections in both males and females (Table 3 ). The manufacturer notes a rate of occurrence in females of $11.4 \%$ with canagliflozin $300 \mathrm{mg}$ and $10.4 \%$ with canagliflozin $100 \mathrm{mg}$ compared to only $3.2 \%$ with placebo in pooled analysis of four placebo-controlled trials. The risk for a mycotic infection is also increased in males $(0.6 \%$ with placebo compared to $3.7 \%-4.2 \%$ incidence with canagliflozin), especially in those who are uncircumcised. Canagliflozin was associated with a similar risk for UTIs as placebo. ${ }^{11}$

As canagliflozin leads to osmotic diuresis, patients may experience orthostatic hypotension, dizziness, hypotension, or syncope. The rate of these reactions is $<5 \%$, but the risk is increased in those receiving a loop diuretic, those older than 75 years of age, and in those with moderate renal impairment (eGFR 30-60 mL/min). Canagliflozin can also modestly increase serum uric acid, blood urea nitrogen, and LDL cholesterol while decreasing eGFR. Elevations in potassium have also been noted in those receiving canagliflozin, with a higher risk in those receiving potassium sparing diuretics and those with reduced renal function. Other reactions occurring at a rate $>2 \%$ include increased thirst, increased urination, nausea, and constipation. ${ }^{11}$

\section{Dosing and administration}

Canagliflozin has been approved by the FDA in two available strengths: a $100 \mathrm{mg}$ oral tablet and a $300 \mathrm{mg}$ oral tablet. It is recommended that canagliflozin be initiated at a dose of $100 \mathrm{mg}$ daily, which can then be titrated to a maximum dose 
Table 3 Adverse reactions

\begin{tabular}{|c|c|c|c|c|c|c|}
\hline Study & $\begin{array}{l}\text { Female mycotic } \\
\text { infection, } \mathrm{n}(\%)\end{array}$ & $\begin{array}{l}\text { Male mycotic } \\
\text { infection, } \mathbf{n}(\%)\end{array}$ & $\begin{array}{l}\text { Urinary tract } \\
\text { infection, } n(\%)\end{array}$ & Pollakuria, n (\%) & Polyuria, n (\%) & $\begin{array}{l}\text { Hypoglycemia, } \\
\text { n (\%) }\end{array}$ \\
\hline \multirow[t]{3}{*}{ Stenlöf et al ${ }^{12}(2013)$} & Pcb: 4 (3.8) & Pcb: 0 & Pcb: 8 (4.2) & Pcb: I (0.5) & Pcb: 0 & Pcb: 5 (2.6) \\
\hline & Cl00: $10(8.8)$ & CI00: 2 (2.5) & CI00: 14 (7.2) & Cl00: 5 (2.6) & CI00: 0 & CI00: 7 (3.6) \\
\hline & C300: 8 (7.4) & C300: 5 (5.6) & C300: $10(5.1)$ & C300: 6 (3) & C300: 6 (3) & C300: 6 (3) \\
\hline Rosenstock et $\mathrm{al}^{13}$ & Pcb: 0 & Pcb: NR & Pcb: 4 (6) & Pcb: $<2 \%$ & NR & Pcb: I (2) \\
\hline \multirow[t]{2}{*}{$(2012)$} & Cl00: 2 (3) & CI00: NR & CI00: 2 (3) & $\mathrm{Cl} 100:<5 \%$ & & CI00: I (2) \\
\hline & C300: I (2) & C300: NR & C300: 2 (3) & C300: $<5 \%$ & & C300: 0 \\
\hline Schernthaner et $\mathrm{al}^{1 / 4}$ & Sit 100: 7 (4.3) & Sit l00: I (0.5) & Sit l00: 2 I (5.6) & Sit l00: 5 (I.3) & Sit 100: 0 & Sit 100: $40.7 \%$ \\
\hline$(2013)$ & C300: 26 (15.3) & С300: $19(9.2)$ & C300: $15(4.0)$ & C300: $6(1.6)$ & C300:3 (0.8) & C300: $43.2 \%$ \\
\hline Devineni et $\mathrm{al}^{15}$ & NR & NR & NR & NR & NR & Pcb: 3 (33) \\
\hline \multirow[t]{2}{*}{$(2012)$} & & & & & & CI00: $6(60)$ \\
\hline & & & & & & C300: 3 (30) \\
\hline Yale et $\mathrm{al}^{16}$ & Pcb: 0 & Pcb: 0 & Pcb: 5 (5.6) & Pcb: I (I.I) & Pcb: 0 & Pcb: $36.4 \%^{\wedge}$ \\
\hline \multirow[t]{2}{*}{$(20 \mid 3)$} & CI00: I (3.I) & CI00: I (I.7) & CI00: 5 (5.6) & CI00: $2(2.2)$ & CI00:0 & CI00: $52.9 \%^{\wedge}$ \\
\hline & C300: I (2.4) & C300: I (2.I) & C300: 7 (7.9) & C300: 4 (4.5) & С300: 0 & C300: $51.2 \%^{\wedge}$ \\
\hline Bode et $\mathrm{al}^{17}$ & Pcb: $2(2 . I)$ & Pcb: 0 & Pcb: $12(5.1)$ & Pcb: 5 (2.I) & Pcb: 0 & Pcb: $33.7 \% \wedge$ \\
\hline \multirow[t]{2}{*}{$(2013)$} & Cl00: 18 (15.4) & Cl00: 4 (3.2) & Cl00: I4 (5.8) & Cl00: $6(2.5)$ & Cl00: 4 (I.7) & CI00: $43.1 \% \wedge$ \\
\hline & C300: 12 (II.2) & C300: 8 (6.2) & C300: $19(8.1)$ & C300: $12(5.1)$ & C300: 4 (I.7) & C300: $47.4 \%^{\wedge}$ \\
\hline
\end{tabular}

Note: ^ Those treated with other hypoglycemic therapy.

Abbreviations: Pcb, placebo; Cl00, canagliflozin 100 mg; C300, canagliflozin 300 mg; NR, not reported; Sit I00, sitagliptin I00 mg.

of $300 \mathrm{mg}$ daily based on response to and tolerability for the medication. It is also advised that canagliflozin be taken prior to the first meal of the day. ${ }^{11}$

The dose of canagliflozin requires adjustment based on renal function. A maximum dose of $100 \mathrm{mg}$ daily should be used in those with an eGFR between $45 \mathrm{~mL} / \mathrm{min}$ and $60 \mathrm{~mL} / \mathrm{min}$. If the eGFR falls below $45 \mathrm{~mL} / \mathrm{min}$, canagliflozin should not be used. Canagliflozin is in a pregnancy risk $\mathrm{C}$ category; women who are nursing should avoid the use of canagliflozin. Increases in AEs in the geriatric population is noted in the labeling of canagliflozin; however, there are no dose adjustments recommended specifically for these patients. Therefore, close monitoring for safety and efficacy should be utilized when using canagliflozin in this population.

\section{Cost}

The cash price for a 1 month supply of canagliflozin is about $\$ 280-\$ 290$, regardless of dose. ${ }^{18}$ This is comparable to other newer medications such as sitagliptin and saxagliptin but about $\$ 100$ less than exenatide. These options are considerably more expensive than agents like metformin and the sulfonylureas, which cost $\$ 10$ or less per month. Insurance coverage will vary, so clinicians will need to consult their local third party formularies and discuss the cost of canagliflozin treatment with their patients.

\section{Unanswered questions}

The effect of canagliflozin, if any, on CV outcomes is of great importance, as it is with any antihyperglycemic agent. This was initially being studied in the Canagliflozin Cardiovascular Assessment Study (CANVAS). CANVAS is a double-blind, placebo-controlled trial that enrolled over 4,000 subjects in the first phase of the study. ${ }^{19}$ Subjects were randomized to placebo or canagliflozin 100 or $300 \mathrm{mg}$ daily. A second, larger phase was originally planned but the researchers had to unblind the Phase I results during the regulatory approval process, and could not proceed to the second phase. ${ }^{19}$ Thus, larger trials of longer duration are still needed with canagliflozin to assess macrovascular outcomes that will significantly assist in ultimately defining its role in management of type 2 diabetes. Another issue that may evolve is whether or not there is any benefit to inhibiting SGLT1 in addition to SGLT2. While SGLT1 only plays a minimal role in glucose reabsorption, there is some evidence that inhibiting both SGLT1 and SGLT2 provides additional glucose lowering, ${ }^{20}$ as inhibition of SGLT1 by canagliflozin doses of $300 \mathrm{mg} /$ day or greater may delay glucose absorption from the gastrointestinal tract and reduce postprandial glucose elevations. ${ }^{10}$

\section{Summary}

Canagliflozin is a novel treatment option for patients with T2DM. By inhibiting the renal reabsorption of glucose canagliflozin reduces the $\mathrm{A}_{1 \mathrm{c}}$ by approximately $0.37 \%-1.16 \%$; body weight and FBG are also reduced with canagliflozin therapy. Canagliflozin is dosed at a starting dose of $100 \mathrm{mg}$ daily that can be increased to $300 \mathrm{mg}$ daily if needed. Canagliflozin carries a very low risk for hypoglycemia but 
appears to increase the risk for genital mycotic infections in both men and women; other potential AEs include increased urination, increased blood urea nitrogen, and serum creatinine, diarrhea, and fatigue. Canagliflozin is unlikely to have drug interactions but does require dose adjustment in patients with a creatinine clearance between 45 and $60 \mathrm{~mL} / \mathrm{min}$; it should not be used in patients with eGFR $<45 \mathrm{~mL} / \mathrm{min}$. Given the favorable efficacy and safety profile of canagliflozin, combined with its novel mechanism of action, canagliflozin represents a welcome addition to the treatment armamentarium for T2DM.

\section{Disclosure}

James R Taylor is on the speakers' bureau for Janssen Pharmaceuticals, Inc. Eric Dietrich and Jason Powell report no conflicts of interest in this work.

\section{References}

1. American Diabetes Association. Diabetes Statistics. Available from http://www.diabetes.org/diabetes-basics/diabetes-statistics/. Accessed September 14, 2013.

2. Mitka M. More patients get good diabetes control, but only a minority meet all goals. JAMA. 2013;309(13):1335-1336.

3. Inzucchi SE, Bergenstal RM, Buse JB, et al; position statement of the American Diabetes Association (ADA) and the European Association for the Study of Diabetes (EASD). Management of hyperglycemia in type 2 diabetes: a patient-centered approach. Diabetes Care. 2012;35(10): 1364-1379.

4. Chao EC, Henry RR. SGLT2 Inhibition - a novel strategy for diabetes treatment. Nat Rev Drug Discov. 2010;9(7):551-559.

5. Wright EM. Renal $\mathrm{Na}+$ glucose cotransporters. Am J Physiol Renal Physiol. 2001;280(1):F10-F18.

6. Mackenzie B, Loo DD, Panayotova-Heiermann M, Wright EM. Biophysical characteristics of the pig kidney $\mathrm{Na}+$ glucose cotransporter SGLT2 reveal a common mechanism for SGLT1 and SGLT2. $J$ Biol Chem. 1996;271(51):32678-32683.

7. Kanai Y, Lee WS, You G, Brown D, Hediger MA. The human kidney low affinity Na+/glucose cotransporter SGLT2. Delineation of the major renal reabsorptive mechanism for D-glucose. J Clin Invest. 1994;93(1): 397-404.
8. Farber SJ, Berger EY, Earle DP. Effect of diabetes and insulin of the maximum capacity of the renal tubules to reabsorb glucose. $J$ Clin Invest. 1951;30(2):125-129.

9. Sha S, Devineni D, Ghosh A, et al. Canagliflozin, a novel inhibitor of sodium glucose co-transporter 2, dose dependently reduces calculated renal threshold for glucose excretion and increases urinary glucose excretion in healthy subjects. Diabetes Obes Metab. 2011;13: 669-672.

10. Polidori D, Sha S, Mudaliar S, et al. Canagliflozin lowers postprandial glucose and insulin by delaying intestinal glucose absorption in addition to increasing urinary glucose excretion: results of a randomized, placebo-controlled study. Diabetes Care. 2013;36(8):2154-2161.

11. INVOKANA ${ }^{\circledR}$ (canagliflozin) [package insert]. Titusville, NJ: Janssen Pharmaceuticals, Inc; 2013.

12. Stenlöf K, Cefalu WT, Kim KA, et al. Efficacy and safety of canagliflozin monotherapy in subjects with type 2 diabetes mellitus inadequately controlled with diet and exercise. Diabetes Obes Metab. 2013;15(4):372-382.

13. Rosenstock J, Aggarwal N, Polidori D, et al; Canagliflozin DIA 2001 Study Group. Dose-ranging effects of canagliflozin, a sodium-glucose cotransporter 2 inhibitor, as add-on to metformin in subjects with type 2 diabetes. Diabetes Care. 2012;35(6):1232-1238.

14. Schernthaner G, Gross JL, Rosenstock J, et al. Canagliflozin compared with sitagliptin for patients with type 2 diabetes who do not have adequate glycemic control with metformin plus sulfonylurea. Diabetes Care. 2013;36(9):2508-2515.

15. Devineni, D, Morrow L, Hompesch M, et al. Canagliflozin improves glycaemic control over 28 days in subjects with type 2 diabetes not optimally controlled on insulin. Diabetes Obes Metab. 2012;14(6): 539-545.

16. Yale JF, Bakris G, Cariou B, et al. Efficacy and safety of canagliflozin in subjects with type 2 diabetes and chronic kidney disease. Diabetes Obes Metab. 2013;15(5):463-473.

17. Bode B, Stenlöf K, Sullivan D, Fung A, Usiskin K. Efficacy and safety of canagliflozin treatment in older subjects with type 2 diabetes mellitus: a randomized trial. Hosp Pract. 2013;41(2):72-84.

18. GoodRx [webpage on the Internet]. Available from: http://www.goodRx. com. Accessed September 15, 2013.

19. Neal B, Perkovic V, de Zeeue D, et al. Rationale, design, and baseline characteristics of the canagliflozin cardiovascular assessment study (CANVAS) - a randomized placebo controlled trial. Am Heart $J$. 2013;166(2);217-223.

20. Zambrowicz B, Freiman J, Brown PM, et al. LX4211, a dual SGLT1/ SGLT2 inhibitor, improved glycemic control in patients with type 2 diabetes in a randomized, placebo-controlled trial. Clin Pharmacol Ther. 2012;92(2):158-169.
Drug Design, Development and Therapy

\section{Publish your work in this journal}

Drug Design, Development and Therapy is an international, peerreviewed open-access journal that spans the spectrum of drug design and development through to clinical applications. Clinical outcomes, patient safety, and programs for the development and effective, safe, and sustained use of medicines are a feature of the journal, which

\section{Dovepress}

has also been accepted for indexing on PubMed Central. The manuscript management system is completely online and includes a very quick and fair peer-review system, which is all easy to use. Visit $\mathrm{http}: / /$ www.dovepress.com/testimonials.php to read real quotes from published authors. 